Research Paper

\title{
Characterization of the effects of defined, multidimensional culture conditions on conditionally reprogrammed primary human prostate cells
}

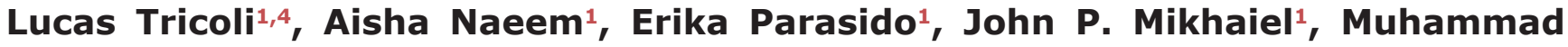 \\ Umer Choudhry ${ }^{1}$, Deborah L. Berry ${ }^{1}$, Iman A. Abdelgawad ${ }^{2}$, Richard J. Lee ${ }^{3}$, Adam \\ S. Feldman ${ }^{3}$, Chukwuemeka Ihemelandu ${ }^{1}$, Maria Avantaggiati ${ }^{1}$, Deepak Kumar ${ }^{4}$, \\ Stephen Byers ${ }^{1}$, Rosa Gallagher ${ }^{5}$, Julia Wulfkuhle ${ }^{5}$, Emanuel Petricoin ${ }^{5}$, Olga \\ Rodriguez $^{1,6}$ and Chris Albanese ${ }^{1,6}$ \\ ${ }^{1}$ Department of Oncology, Lombardi Comprehensive Cancer Center, Georgetown University Medical Center, Washington, DC, USA \\ ${ }^{2}$ National Cancer Institute of Egypt, Cairo, Egypt \\ ${ }^{3}$ Massachusetts General Hospital Cancer Center, Boston, MA, USA \\ ${ }^{4}$ Julius L. Chambers Biomedical/Biotechnology Research Institute, North Carolina Central University, Durham, NC, USA \\ ${ }^{5}$ Center for Applied Proteomics and Molecular Medicine, George Mason University, Manassas, VA, USA \\ ${ }^{6}$ Preclinical Imaging Research Laboratory, Georgetown University Medical Center, Washington, DC, USA \\ Correspondence to: Chris Albanese, email: albanese@georgetown.edu \\ Keywords: prostate; cancer; primary tissue; reprogrammed cells; androgen \\ Received: October 26, $2017 \quad$ Accepted: November 02, 2017 Published: December 18, 2017 \\ Copyright: Tricoli et al. This is an open-access article distributed under the terms of the Creative Commons Attribution License 3.0 \\ (CC BY 3.0), which permits unrestricted use, distribution, and reproduction in any medium, provided the original author and source \\ are credited.
}

\section{ABSTRACT}

The inability to propagate human prostate epithelial cells indefinitely has historically presented a serious impediment to prostate cancer research. The conditionally reprogrammed cell (CRC) approach uses the combination of irradiated J2 mouse fibroblasts and a Rho kinase inhibitor such as Y27632 to support the continuous culture of cells derived from most epithelial tissues, including the prostate. Due to their rapid establishment and overall ease of use, CRCs are now widely used in a variety of basic and preclinical settings. In addition, CRCs were successfully used to clinically treat respiratory papillomatosis. Although both normal and tumorderived prostate CRCs have been used to study the basic biology of prostate cancer and to test new therapies, certain limitations exist. We have previously reported that prostate CRCs form functional prostate glands when implanted under the mouse renal capsule. However in conventional culture, the prostate CRCs exist in an adult stem-like, transient amplifying state and consequently do not adequately recapitulate several important features of a differentiated prostate epithelium. To address these limitations, we previously described a transwell dish-based model that supported the culturing of prostate CRCs and the collection of cells and cell extracts for molecular and genetic analyses. Using normal and tumor-derived prostate CRCs, we describe the combined effects of the multi-dimensional transwell platform and defined culture media on prostate cellular proliferation, differentiation and signaling. 


\section{INTRODUCTION}

According to the American Cancer Society, the risk of prostate cancer $(\mathrm{PCa})$ increases dramatically after age 50, and the usefulness and benefits of PSA testing for risk stratification has been vigorously debated [1]. As such, PCa remains the second leading cause of cancer related death in American men, and the American Cancer Society reports that approximately 180,000 new cases of prostate cancer and over 26,000 deaths occurred in 2016. Additionally, for patients whose disease has recurred after primary treatment, disease management remains complicated. Androgen deprivation therapy (ADT) is an effective first line therapy for locally advanced or metastatic disease. Unfortunately, once PCa recurs, the eventual development of castration-resistant prostate cancer (CRPC) remains an incurable disease and more effective therapies are needed [2].

Until recently, genetically engineered mice, patientderived xenografts (PDX) and commercially available transformed cell lines have been the main models for prostate cancer research. While PDX mice are a useful model system, they can be difficult to establish, expensive to maintain and do not support the capacity for cellular modifications. In addition, PDX is a very low throughput approach, limiting its use in drug discovery and/or personalized PCa treatment. The widely used transformed $\mathrm{PCa}$ cell lines have yielded important information about prostate cancer progression and treatment. However, limitations exist with these cell lines in that they only represent a small component of the human disease [3] and, as a result, the critical need to develop more clinically relevant models persists.

Two recent advances in primary cell culture technologies, the organoid approach for prostate [4] and pancreatic [5] cancers and our conditionally reprogrammed cell (CRC) approach that effectively supports all epithelial tissues tested [6-8], have begun to address the need for sustainable cultures of primary human cells from both normal and cancerous epithelial tissues. Specifically, we and others have shown that the CRC approach, a combination of irradiated J2 mouse fibroblasts and a Rho kinase inhibitor (e.g. Y-27632), is an extremely robust methodology for enabling the indefinite propagation of primary cells from both normal and malignant epithelial tissues [7-15]. For example, we have used the CRC platform for the successful identification of the molecular basis of a rare form of cervical cancer [15] and importantly, for rapidly identifying an FDA-approved drug, vorinostat, to treat a case of recurrent respiratory papillomatosis in a patient who had failed a number of previous drug treatments [10].

CRCs have been widely used to study the basic biology of prostate cancer [16] and to define potential new therapies for its treatment [11-14]. In addition, CRCs have been generated and used for breast cancer research
[17], for cystic fibrosis research [18, 19], to investigate drug sensitivity and resistance in lung cancer [20] attesting to the unprecedented broad applicability of this culture technology.

While this ability to derive primary cell cultures from prostate tissue has bona fide utility for prostate cancer research and therapeutic development, certain limitations currently exist. For example, our previous studies have found that both normal and tumor-derived $\mathrm{CRC}$ cultures contain cell populations that express basal cell markers, CD44 and Trop2 (CD49f), the luminal marker CD13 and a small population of CD117-expressing cells [16]. In addition, the expression of the basal cell marker cytokeratin 5 and the luminal cell markers cytokeratin 8/18 as well as low-level androgen receptor (AR) expression are all observed under conventional culture conditions $[14,16]$. Perhaps not surprisingly, these cells also express the proliferative/basal cell marker p63 [16], indicating that prostate CRCs exist in a transient amplifying (TA), adult stem-like state with sub-optimal androgen sensitivity. Importantly, however, we have recently shown that long-term cultures of normal human prostate CRCs formed well-differentiated prostate glandular structures, and inclusive of nuclear localization of the AR and luminal prostatic secretions, when implanted under the mouse renal capsule [8]. These data clearly establish that conventional two-dimensional (2D) CRCs retain their lineage commitment and the ability to differentiate when placed in a permissive environment.

To support the growth of prostate CRCs in an in vitro environment that supports a more differentiated phenotype, we generated a filter-based multi-dimensional culture technique [21]. This transwell-dish culture method (TDCM) was initially described using cancer-derived CRCs from a patient with Gleason 6 prostate cancer [11]. When placed in the TDCM environment, subpopulations of cells were observed that expressed p63, suggestive of basal and proliferating cells, the AR, suggestive of luminal cells and in some cases both markers [21], perhaps indicative of transient cells. We also described the methods needed to recover CRCs from the filters and to collect nucleic acid and protein extracts from the cells in the TDCM system [21].

We have herein extended these initial studies to include both the normal and malignant (Gleason 6 and Gleason 8) prostate CRCs from two patients. We define the effects of TDCM on the expression of stem cell markers, and on proliferation and differentiation, and compare the TDCM cells to both CRCs grown in conventional twodimensional cultures (i.e. plastic dishes) and to primary prostate tissue.

This study establishes that the TDCM platform enables the multi-dimensional culturing of normal and tumor-derived prostate CRCs and that these culture conditions supported the development of a more mature, prostate epithelial phenotype. Importantly, neither 
Table 1: Composition of defined medias

\begin{tabular}{|c|c|c|c|c|c|c|c|}
\hline DM1 & $30 \mathrm{nM}$ citrate & $1 \mathrm{nM}$ zinc & 5nM DHT & l & I & l & / \\
\hline DM2 & $30 \mathrm{nM}$ citrate & $1 \mathrm{nM}$ zinc & $5 \mathrm{nM}$ DHT & $20 \mathrm{ng} / \mathrm{mL} \mathrm{HGF}$ & l & $10 \mathrm{ng} / \mathrm{mL} \mathrm{TGFb}$ & I \\
\hline DM3 & $30 \mathrm{nM}$ citrate & $1 \mathrm{nM}$ zinc & 5nM DHT & $20 \mathrm{ng} / \mathrm{mL} \mathrm{HGF}$ & $10 \mathrm{ng} / \mathrm{mL}$ IGF1 & l & / \\
\hline DM4 & $30 \mathrm{nM}$ citrate & $1 \mathrm{nM}$ zinc & $5 \mathrm{nM}$ DHT & I & $10 \mathrm{ng} / \mathrm{mL}$ IGF1 & $10 \mathrm{ng} / \mathrm{mL} \mathrm{TGFb}$ & I \\
\hline DM5 & $30 \mathrm{nM}$ citrate & $1 \mathrm{nM}$ zinc & $5 \mathrm{nM}$ DHT & / & $10 \mathrm{ng} / \mathrm{mL}$ IGF1 & / & $10 \mathrm{ng} / \mathrm{mL}$ VitD3 \\
\hline DM6 & $30 \mathrm{nM}$ citrate & $1 \mathrm{nM}$ zinc & 5nM DHT & $20 \mathrm{ng} / \mathrm{mL} \mathrm{HGF}$ & $10 \mathrm{ng} / \mathrm{mL}$ IGF1 & / & $10 \mathrm{ng} / \mathrm{mL}$ VitD3 \\
\hline DM7 & $30 \mathrm{nM}$ citrate & $1 \mathrm{nM}$ zinc & 5nM DHT & $20 \mathrm{ng} / \mathrm{mL}$ HGF & $10 \mathrm{ng} / \mathrm{mL}$ IGF1 & $10 \mathrm{ng} / \mathrm{mL} \mathrm{TGFb}$ & 1 \\
\hline
\end{tabular}

enhanced cell death nor senescence were observed after a week in the TDCM environment. Collectively, the combination of the patient-derived CRCs and the TDCM platform represents an innovative new tool for basic and translational studies of prostate cancer, as well as for investigations into normal prostate development.

\section{RESULTS}

\section{Defined media selection}

In order to promote the transition of the CRCs from their transient amplifying, stem-like state to a more luminal phenotype, a series of defined media (DM) were formulated (Table 1). The normal prostate CRCs from Patient 1 were cultured for one week in conventional in vitro conditions, using either standard CRC conditioned media (CM) [22] or defined media (DM). Western blotting was performed to determine the expression of luminal markers AR and $\mathrm{p} 27^{\mathrm{kip} 1}$ and the proliferative/basal marker, p63. $\beta$-actin was used as a loading control. As shown in Figure 1, DM5 and DM6, which contained Vitamin D3, known to regulate prostate cell proliferation [23], had the largest effects on p2 $7^{\mathrm{kip} 1}$ and p63 expression. DM5 (referred to simply as DM) was chosen for all subsequent experiments.

\section{The transwell dish culture method (TDCM)}

As stated above, the TDCM system, shown schematically in Figure 2A, was initially defined using the Gleason 6 CRCs from Patient 1, wherein we found that the system supported both $\mathrm{p} 63$ positive basal-like cells and AR-positive luminal cells [21]. The methodological approaches required to recover the CRCs from the filters and to collect cell extracts from the inserts were also previously described [21]. Briefly, $6 \times 10^{5}$ CRCs were seeded on the filter insert and CM containing $10 \mathrm{uM}$ Y-27632 was placed in both the upper and lower chambers. After 7 days, DM or CM was applied to the top chamber and fresh $\mathrm{CM}$ was added to the bottom chamber. We have now extended our studies to include and compare both normal and tumor CRCs from Patients 1 (Gleason 6) and 2 (Gleason 8 ) in order to more fully define the phenotypic effects of TDCM on both normal and tumor-derived prostate CRCs. The cytogenetic profiles of the tumorderived CRCs are shown in Supplementary Figure 1.

\section{Phenotypic effects of CRCs growing under conventional and TDCM conditions}

To define the morphological changes occurring in response to DM or growth in the TDCM system, images were collected following culture in the different

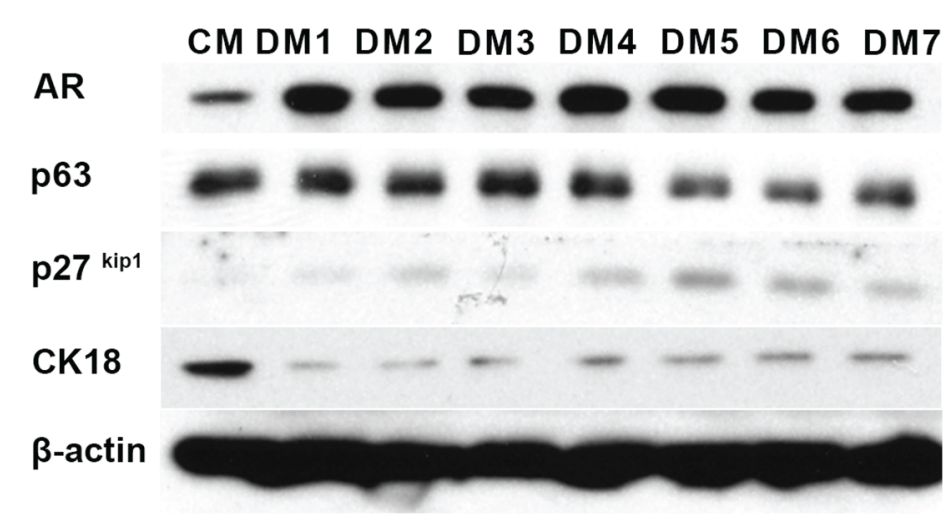

Figure 1: Defined media testing. Western blotting of protein extracts of normal prostate CRCs from Patient 1. The cells were cultured for 7 days in either conditioned media (CM) or the defined medias (DM) listed in Table 1. CK18: cytokeratin 18. $\beta$-actin was used as a loading control. 
conditions for seven days. As seen in Figure 2B and 2C, both the normal and tumor derived CRCs from Patient 2 show the typical, small cuboidal morphology of CRCs in conventional culture. Upon culturing in DM for one week, the cells became significantly larger (with an average cell diameter of $80.3 \pm 25.2$ um vs. $40.3 \pm 9.8 \mathrm{um}, \mathrm{p}<0.001)$ with a darker and more distinctive nucleus.

The CRCs were next seeded into the TDCM system (as described in the Methods and in [21]). When cultured with $\mathrm{CM}$ in the bottom and top chambers, both the normal CRCs and tumor-derived CRCs appear tightly packed and aggregated on the filter surface (Figure 2B panels $\mathrm{i}$ and ii and Figure $2 \mathrm{C}$ panels $\mathrm{i}$ and ii, respectively). Similarly, when the CRCs were cultured with CM in the lower chamber and DM in the top chamber for seven days, they continued to display a tightly packed configuration across the filter surface (Figure 2B panels iii, iv and Figure $2 \mathrm{C}$ panels iii and iv). The filters were then carefully
A.

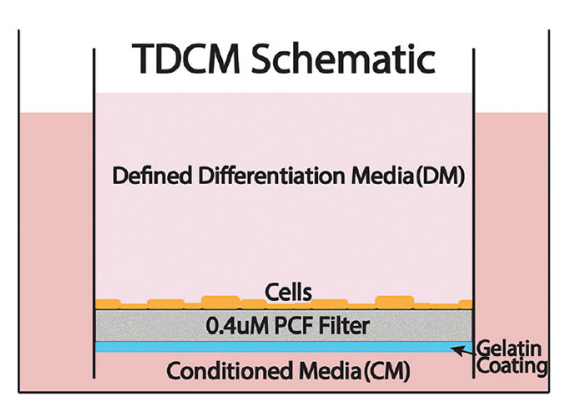

B.

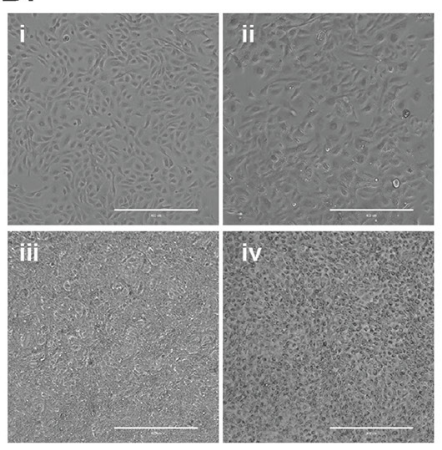

C.

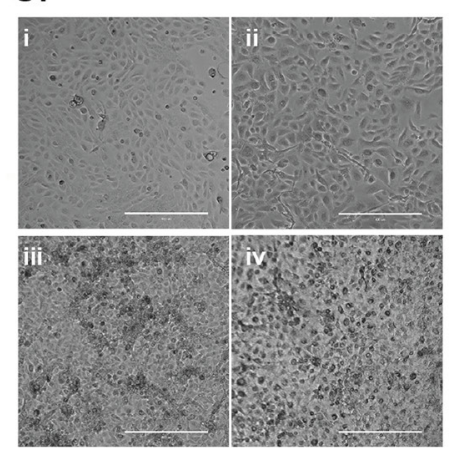

Figure 2: Culture conditions and cell morphology. (A) Schematic of the TDCM (transwell dish culture method) platform. Micrographs of (B) normal and (C) tumor derived CRCs in i) conventional culture with CM, ii) conventional culture with DM, iii) TDCM with CM, iv) TDCM with DM. CM; conditioned media. DM; defined media. Scale bar, 400um.
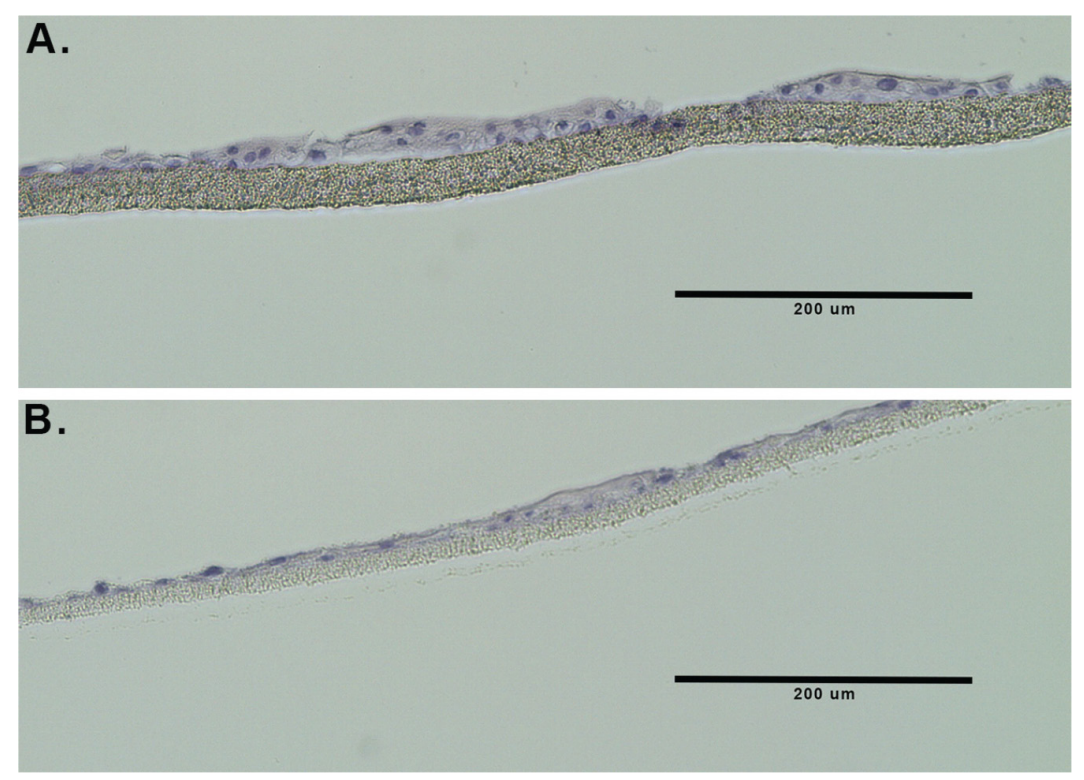

Figure 3: TDCM histology. Hematoxylin and eosin- stained sections of formalin-fixed, paraffin-embedded CRCs from (A) normal prostate CRCs and (B) tumor-derived prostate CRCs. 
removed from the inserts as described in detail in [21] for histological analyses. Representative histological sections are shown in Figure 3. As previously seen with the cancerderived CRCs from Patient 1, both the normal (Figure 3A) and malignant CRCs from Patient 2 (Figure 3B) formed stratified cultures that adhered to the filter surface, forming an organized layer of cells.

Immunofluorescent (IF) staining of p63 and the AR was performed on both the normal and tumor-derived CRCs from Patient 2 (Figure 4). The cells were co-stained with DAPI to identify the nuclei. Similar to the tumor cells from Patient 1 [21], a subset of both the normal and tumor-derived CRCs from Patient 2 exhibited nuclear AR staining (green fluorescence), a feature consistent with prostate luminal cells. However since diffuse cytoplasmic
AR staining was also observed, confocal imaging was performed and IF images captured in $1.5 \mathrm{um}$ increments (Figure 4C-4E), confirming that a significant proportion of the AR signal was indeed localized within the nucleus.

In some cells, the IF staining also established the presence of nuclear p63 (red fluorescence), indicative of a proliferative, more basal-like layer of cells. A subset of the CRCs co-stained for both the AR and p63, which may be indicative of either transient amplifying cells or, in the case of the tumor-derived CRCs, proliferating tumor cells.

We conclude that the TDCM system supports the growth and stratification of normal and tumor CRCs with phenotypic features that resemble the prostate epithelium, including cells with luminal, basal and/or TA markers.
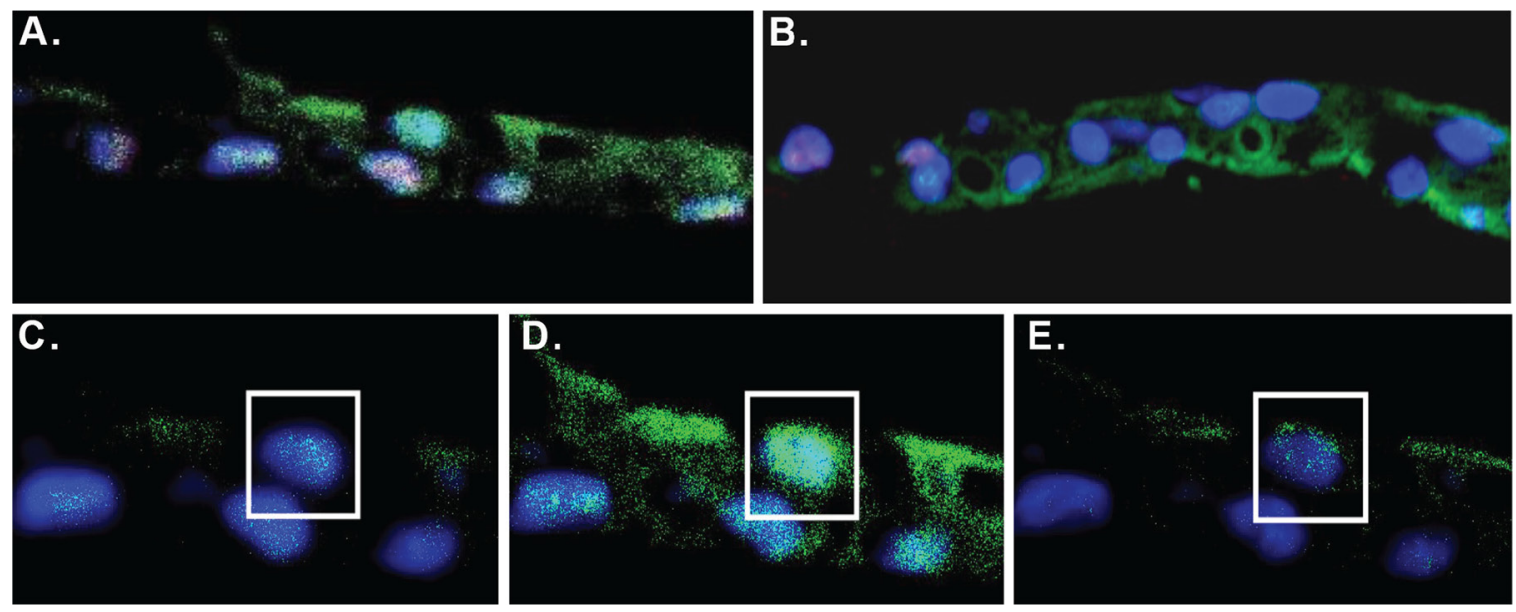

Figure 4: Immunofluorescent staining of CRCs. (A) Normal and (B) tumor derived CRCs were cultured on the TDCM platform. Fixed paraffin sections were immunostained for the androgen receptor (green) and p63 (red). The cells were counterstained with DAPI (blue). (C-E) Confocal images of the sample in (A) taken at 1.5 micron increments.

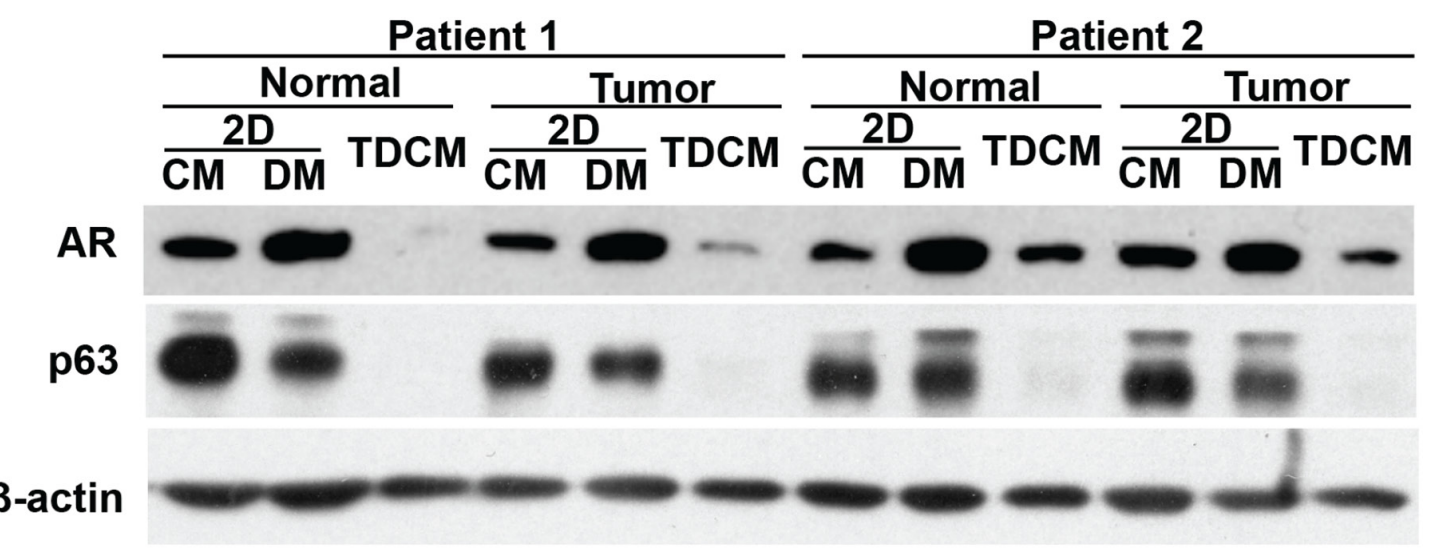

Figure 5: Conventional versus TDCM cultures. Western blotting for the androgen receptor (AR) and p63. Normal and tumor CRCs from Patients 1 and 2 were cultured for 7 days as conventional cultures (2D) in either conditioned media (CM) or defined media (DM) or in the TDCM system with DM. $\beta$-actin was used as a loading control. 


\section{Molecular analysis}

To define the effects of the TDCM on the protein markers indicative of proliferation and differentiation of the prostate CRCs, the levels of the AR and p63 were assessed by western blotting. As was seen in Figure 1 , the levels of the AR increased and p63 decreased in the conventional cultures grown in DM (Figure 5). Interestingly, despite robust nuclear localization of the AR (Figure 4), total AR expression decreased in the TDCM/ DM cells (Figure 5). The AR has been shown to possess an auto-feedback repressor function, acting via intron 2 of the $A R$ gene [24] and this negative feedback loop may indeed be intact in the TDCM platform. A decrease in $\mathrm{p} 63$ expression was also observed.

Human ectocervical CRCs express stem cell markers, such as Oct4, Sox2 and Nanog albeit at levels lower those found in mesenchymal stem cells [9]. To characterize expression of these markers in prostate CRCs, western blotting was performed. LNCaP cells were used as a negative control. When carried as conventional cultures in either CM or DM, the CRC lines all expressed Oct4, Nanog and Sox2 (Figure 6). Conversely, a significant loss of expression of these proteins was observed when cultured under the TDCM conditions, with the most pronounced changes observed in the tumor-derived CRCs (Figure 6). The TDCM conditions also resulted in an increase in PSA expression (Supplementary Figure 2). Collectively, the above data indicate that the TDCM/DM platform rapidly enables the CRCs to adopt a more differentiated phenotype with a concomitant suppression of the stem- and transient amplifying- like characteristics commonly associated with CRCs in conventional culture conditions.

\section{Comparison of CRCs to patient tissue samples}

To better compare the CRCs to intact prostate tissue, reverse-phase protein array (RPPA) analyses were performed on extracts from the 2D and TDCM culture systems and compared against laser-capture microdissected (LCM) primary prostate cancer samples. The LCM and the RPPA pathway activation mapping analysis, covering 159 key signaling proteins and phosphoproteins from pathways known to be involved in tumorigenesis (growth, survival, apoptosis, autophagy, motility, inflammation, etc.) (Figure 7), were performed as previously described [25]. While the different sample types (LCM, TDCM, conventional CRCs) all clustered separately, the TDCM cells clustered more closely with the LCM samples. Furthermore, a number of key proteins, including cyclin D1 (which we have shown to repress AR activity [26]), receptor tyrosine kinases such as ALK and cMET as well as many members of the translation (e.g ribosomal S6 protein) and survival (e.g., BAD and LAMP2) signaling pathways were comparably expressed in the LCM and TDCM samples versus conventional CRC cultures (Supplementary Figure 3).

We next sought to define the cellular and molecular changes brought about by the culture media per se. A hierarchical two-way clustering analysis was performed on a subset of the data from conventionally cultured CRCs and focused on proteins involved in proliferation. As seen in Figure 8A, the cells from Patient 2 clustered based on tissue origin (normal vs tumor), with the proteins in Clusters 1 and 2 being a major component of the clustering that was independent of the culture media (Figure 8B). These data suggest that major components of the proteomic signature in the Gleason 8 CRCs are more strongly influenced by the genetic and molecular changes associated with prostate cancer than by the culture media.

Further unsupervised hierarchical analyses focused on proteins involved in MAPK and mTOR signaling and protein translation. When comparing the CRCs against localized PCa (samples 4201_LCM, P430_LCM and P4501_LCM) and CRPC (TURP1_LCM_\#3, TURP1_

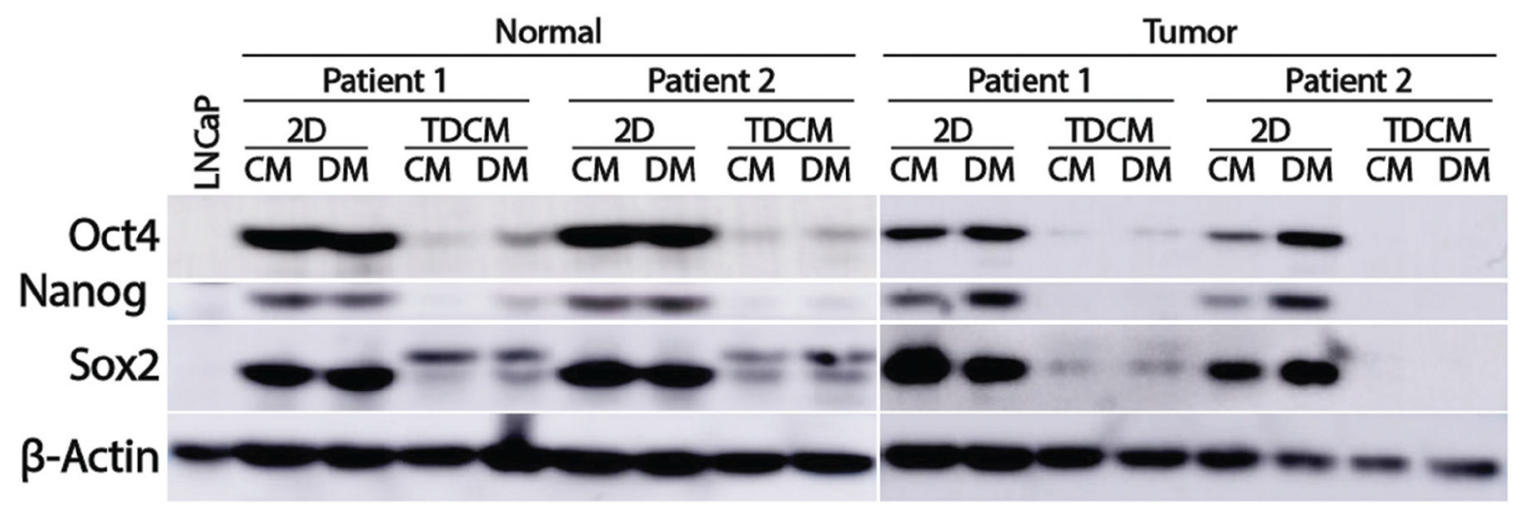

Figure 6: Culture conditions and effects on stem cell markers. Normal and tumor-derived CRCs from Patients 1 and 2 were cultured for 7 days in either conventional cultures (2D) or in the TDCM system in either conditioned media (CM) or defined media (DM). $\beta$-actin was used as a loading control. 
LCM_\#4 and TURP2_LCM), the TDCM cells clustered with the localized PCa samples while a subset of the proteins in the conventional cultures (e.g. total mTOR, Jak Y1007, PTEN S380) clustered with the TURP CRPC samples (Figure 9).

\section{Transcriptomic analyses}

RNA microarray analyses were performed on Patient 2's tumor CRCs cultured under TDCM conditions vs. conventional CRCs and 157 genes were significantly upregulated (fold change $>1.5$ ) and 3092 genes were significantly down regulated (fold change $>-1.5$, p-value $<0.001$, Q-value $<0.015$ ) in TDCM $v s$. conventional CRC culture conditions. The top 20 genes that were either induced or repressed in TDCM vs. 2D CM conditions are shown (Figure 10). Among the genes induced in the TDCM cells, two are associated with responses to hypoxia ( $A N K R D 37, E G L N 3$ ), five are associated with immunity (RSAD2, WFDC2, IFIT3, BST2, HLA-B), and a vitamin D3 responsive gene (TREM1). In addition, there were multiple genes induced that are involved with cell and organelle structure and function ( $P N C K, U B D, C D H 2$, $H E R C 5)$ and importantly, genes associated with the prostate, $\mathrm{AR}(M M P 7, C D H 2, E N O 2, I G F B P 3)$ and cancer (IFIT3, IFI44L). Among the genes repressed by TDCM are those involved in cell cycle progression $(C C N B 2$, $C D C 20, T O P 2 A, H O P X)$ and in cell adhesion and migration (SERPINB2, SPINK7, CAPN14). In addition, stem markers and genes not normally associated with prostate were also suppressed (MAL, KRT4, SPRR2E, SPRR2D. SPRR1A, SPRR1B, FST). The induction of c-jun (Supplementary Table 1) was also observed under TDCM conditions.

Finally, pathway analyses were performed using Ingenuity Pathway Analysis (IPA@Qiagen). Our IPA data established that the TDCM conditions significantly altered the levels of mRNAs that were enriched in canonical pathways such as senescence, Rac, PPAR, EIF2, HIPPO, p70S6K and mammalian target of Rapamycin (mTOR) signaling (Figure 11). It is important to note that the senescence-associated pathway was suppressed in our TDCM condition. Out of 455 genes associated with the senescence pathway, 185 genes were down regulated by TDCM vs. conventional culture versus 12 genes induced by TDCM, indicating that despite being in the TDCM system for over one week, the cells were healthy and viable. In addition, the activation of the HIPPO, G1/S checkpoint regulation, Rho-GDI, PPAR and $\beta$-catenin signaling were indicative of the overall improved health of the cells grown under TDCM conditions.

Thus our IPA analyses indicate that TDCM platform supports the continued vibrancy of the cells within the stratified cell layers.

\section{DISCUSSION}

Existing models of continuous, long-term cultures of primary human prostate cells are currently restricted to either the R-spondin/organoids or our CRC-based

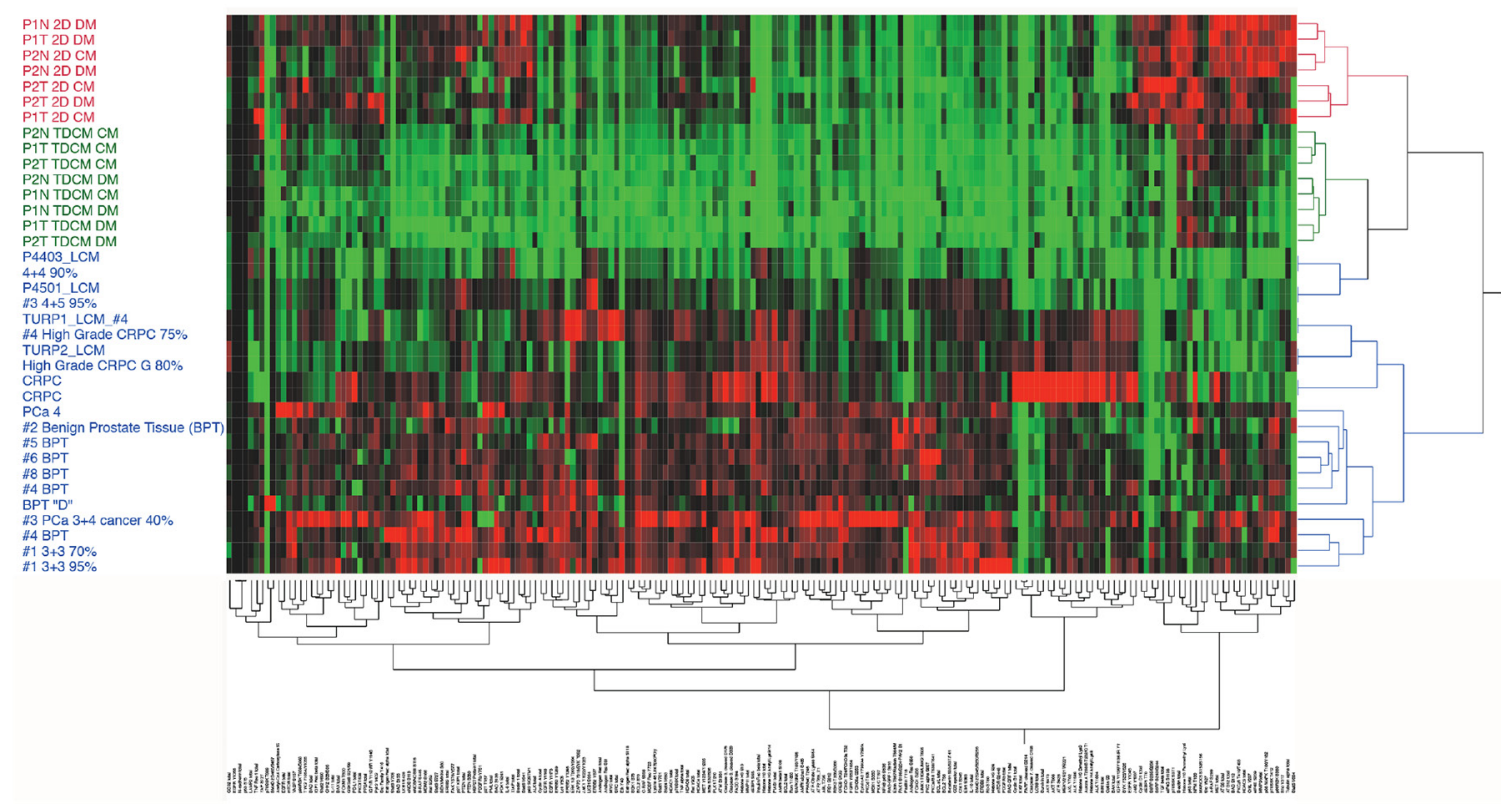

Figure 7: Unsupervised hierarchical clustering. Reverse phase protein arrays were run on CRCs in either conventional culture or in the TDCM platform and compared to laser capture microdissected (LCM) primary prostate tissue. A panel of 159 protiens and phosphoproteins was used. 
methodology. While both of these approaches have unique strengths and weaknesses, perfecting these platforms through iterative modification and validation is vital to expanding their experimental and, ultimately, clinical use. We have therefore developed the TDCM system [21], and herein define its impact on the morphological

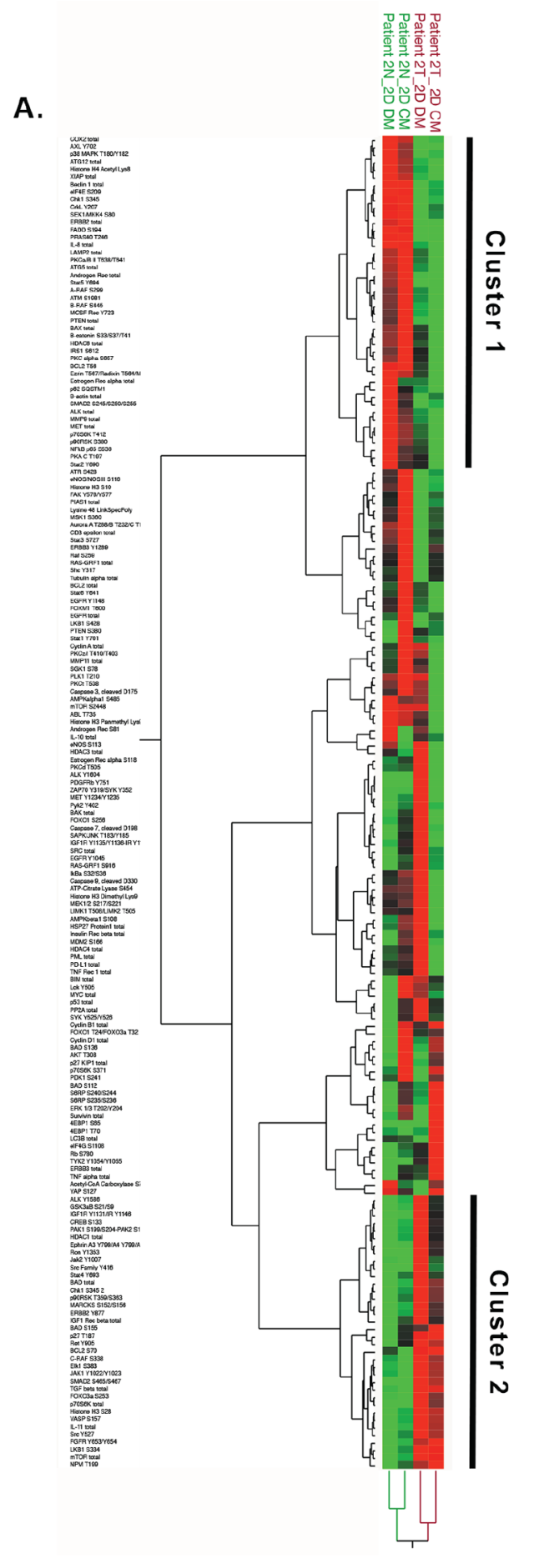

and molecular phenotypes of normal and cancer-derived primary prostate cells.

The benefits of TDCM were apparent throughout the study. For example, while morphological changes, such as alterations in the typical cuboidal cell shape and increased size and darkening of nuclei, were detected within one week of conventional culture in DM, cells in the TDCM
B.

\begin{tabular}{|l|l|}
\hline \multicolumn{1}{|c|}{ Cluster 1 } & \multicolumn{1}{|c|}{ Cluster 2 } \\
\hline COX2 total & ALK Y1586 \\
\hline AXL Y702 & GSK3aB S21/S9 \\
\hline p38 MAPK T180/Y182 & IGF1R Y1131/IR Y1146 \\
\hline ATG12 total & CREB S133 \\
\hline XIAP total & PAK1 S199/S204-PAK2 S192/S197 \\
\hline Histone H4 Acetyl Lys8 & HDAC1 total \\
\hline Beclin 1 total & Ephrin A3 Y799/A4 Y799/A5 Y833 \\
\hline elF4E S209 & Ron Y1353 \\
\hline Chk1 S345 & JAK1 Y1022/Y1023 \\
\hline CrkL Y207 & Src Family Y416 \\
\hline SEK1/MKK4 S80 & Stat4 Y693 \\
\hline ERBB2 total & BAD total \\
\hline FADD S194 & Chk1 S345 \\
\hline PRAS40 T246 & p90RSK T359/S363 \\
\hline IL-8 total & MARCKS S152/S156 \\
\hline LAMP2 total & ERBB2 Y877 \\
\hline PKCa/B II T638/T641 & IGF1 Rec beta total \\
\hline ATG5 total & BAD S155 \\
\hline Androgen Rec total & p27 T187 \\
\hline Stat5 Y694 & Ret Y905 \\
\hline A-RAF S299 & BCL2 S70 \\
\hline ATM S1981 & C-RAF S338 \\
\hline B-RAF S445 & Elk1 S383 \\
\hline MCSF Rec Y723 & JAK1 Y1022/Y1023 \\
\hline PTEN total & SMAD2 S465/S467 \\
\hline BAX total & TGF beta total \\
\hline B-catenin S33/S37/T41 & FOXO3a S253 \\
\hline HDAC6 total & p70S6K total \\
\hline IRS1 S612 & Histone H3 S28 \\
\hline PKC alpha S657 & VASP S157 \\
\hline BCL2 T56 & IL-11 total \\
\hline Ezin T567/Radixin T564/Moesin T558 & Src Y527 \\
\hline Estrogen Rec alpha total & FGFR Y653/Y654 \\
\hline p62 SQSTM1 & LKB1 S334 \\
\hline B-actin total & mTOR total \\
\hline SMAD2 S245/S250/S255 & NPM T199 \\
\hline ALK total & \\
\hline MMP9 total & \\
\hline MET total & \\
\hline p70S6K T412 & \\
\hline p90RSK S380 & \\
\hline NFkB p65 S536 & \\
\hline PKA C T197 & \\
\hline Stat2 Y690 & \\
\hline
\end{tabular}

Figure 8: Protein analyses of cells in conventional culture. (A) Unsupervised hierarchical clustering of the reverse phase protein array data from normal ( $\mathrm{N}$, green font) and tumor-derived ( $\mathrm{T}$, red font) $\mathrm{CRCs}$ from Patient 2, cultured in either CM (conditioned media) or DM (defined media). (B) List of proteins increased (Cluster 1) or decreased (Cluster 2) in tumor versus normal CRCs. 
system adopted a stratified structure, resembling prostate epithelium. In addition, while the levels of the stem markers, Oct4, Nanog and Sox2, were not significantly altered by DM, both normal and tumor-derived CRCs cultured under TDCM conditions showed a significant to near complete loss in expression of these proteins, indicative of a shift away from transiently amplifying, stem-like cells. A decrease in overall AR expression was seen in TDCM cells, which may be attributed to the negative feedback loop that has been documented in the AR pathway [24]. Our analyses also predict an activation of nuclear AR under TDCM conditions, as the inhibition of cyclin D1 (Supplementary Figure 3) and the induction of c-jun (Supplementary Table 1) suggests that AR function is at least partially restored under these conditions, consistent with our immunofluorescent data (Figure 4) These data are further supported by changes in the androgen biosynthetic pathway, with increased expression of testosterone 17beta dehydrogenase (Supplementary Table 1) and the observation that prostate specific antigen levels were increased in TDCM cells (Supplementary Figure 2). It is clear, however, that the terminal luminal differentiation achieved in vivo [8] remained partially incomplete.

While the TDCM proteome clusters predominantly with the primary tissue samples, there are key proteins that remain distinct. This raises the possibility that media conditions may need to be modified and/or that additional time in TDCM may be required. It also must be noted that the in vivo renal capsule transplantation experiments [8] were carried out over four or more months, and it is possible that the 7 days in DM were not sufficient for full engagement of the AR. The activation of Hippo signaling, PPAR signaling and wnt $/ \beta$-catenin signaling indicated that cell's nutrient uptake capability and overall epithelial-

P1N 2D CM
P2N TDCM DM
P1N TDCM DM
P2T TDCM DM
P1T TDCM DM
4201_LCM
P4403_LCM
P1N TDCM CM
P1T TDCM CM
P2T TDCM CM
P4501_LCM
TURP1_LCM_\#3
TURP1_LCM_\#4
TURP2_LCM
P1N 2D DM
P1T 2D DM
P2N 2D CM
P2N 2D DM
P2T 2D CM
P2T 2D CM
P2T 2D DM
P2T 2D DM
P1T 2D CM
P2N TDCM CM

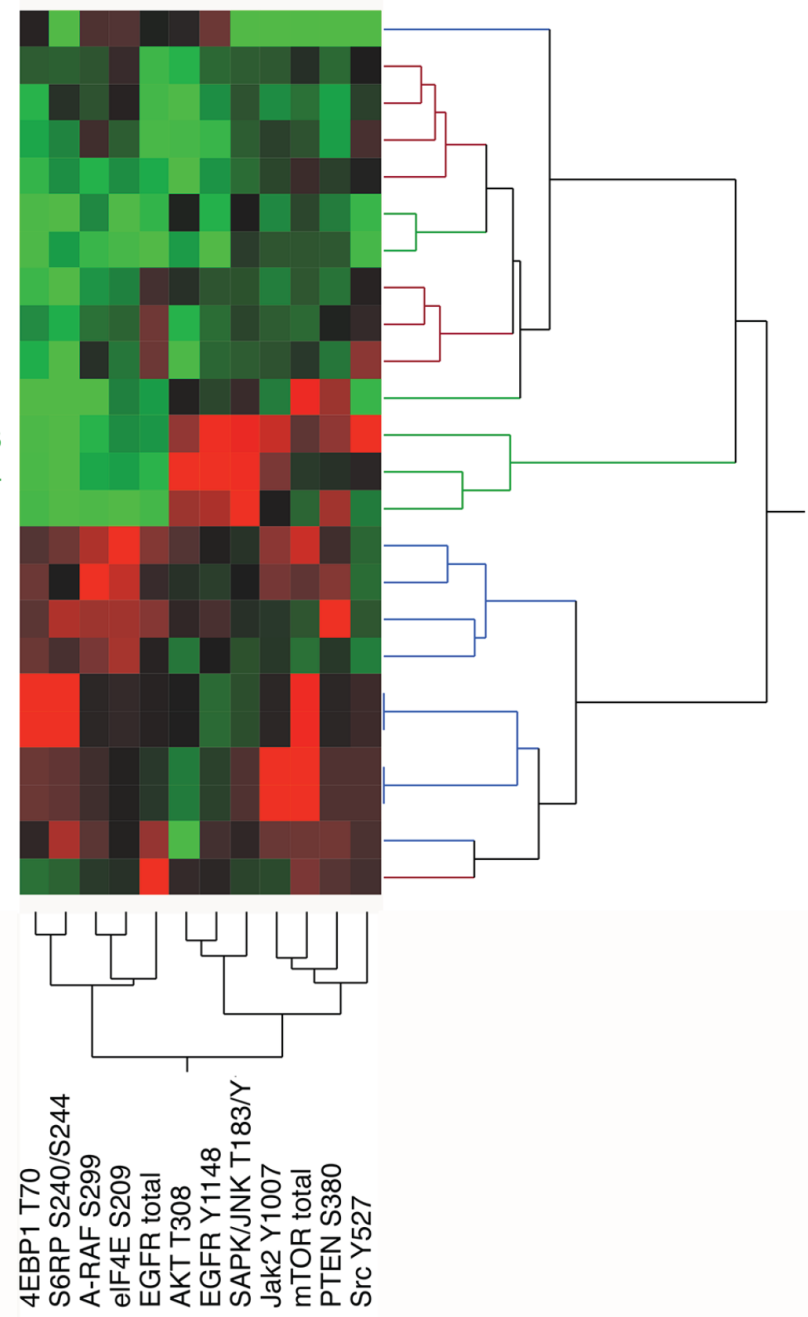

Figure 9: Unsupervised hierarchical analyses. The protein array data from normal $(\mathrm{N})$ and tumor (T) cells from Patient 1 (P1) and Patent 2 (P2,) were compared against LCM (laser capture microdissected) castrate resistant (TURP1, TURP2) and localized cancer samples. TDCM, conventional cultures (2D) and either conditioned media (CM) or defined media (DM) conditions were used. 
associated gene expression profile was improved in TDCM conditions. Further, the near complete absence of a senescence-promoting profile, the reductions in apoptosis signaling and the lack of induction of a strong p53 signature, establish that the TDCM conditions provide a supportive environment for longer term experiments.

The normal prostate, as well as localized prostate tumors, develop and persist in a complex stromal microenvironment. For example, prostate ducts are

A.

\begin{tabular}{|c|c|c|c|c|c|c|}
\hline $\begin{array}{l}\text { Gene } \\
\text { Symbol }\end{array}$ & Entrez Gene Name & FC & P-value & Q-value & Location & Type(s) \\
\hline MMP7 & matrix metallopeptidase 7 & 33.502 & $5.22 \mathrm{E}-10$ & $9.17 \mathrm{E}-06$ & Extracellular Space & peptidase \\
\hline TREM1 & triggering receptor expressed on myeloid cells 1 & 21.152 & $3.18 \mathrm{E}-07$ & 1.59E-04 & Plasma Membrane & TM receptor \\
\hline RSAD2 & radical S-adenosyl methionine domain containing 2 & 13.781 & 8.44E-05 & 3.50E-03 & Cytoplasm & enzyme \\
\hline PNCK & pregnancy up-regulated nonubiquitous CaM kinase & 13.021 & $5.64 \mathrm{E}-07$ & $2.24 \mathrm{E}-04$ & Other & kinase \\
\hline IGFBP3 & insulin like growth factor binding protein 3 & 13.012 & 4.14E-07 & $1.83 \mathrm{E}-04$ & Extracellular Space & other \\
\hline ANKRD37 & ankyrin repeat domain 37 & 11.758 & $1.42 \mathrm{E}-04$ & $4.68 \mathrm{E}-03$ & Cytoplasm & other \\
\hline CASP14 & caspase 14 & 11.741 & 1.10E-08 & 2.73E-05 & Cytoplasm & peptidase \\
\hline ENO2 & enolase 2 & 10.482 & $1.95 \mathrm{E}-09$ & 1.15E-05 & Cytoplasm & enzyme \\
\hline $\mathrm{CDH} 2$ & cadherin 2 & 10.407 & $1.61 \mathrm{E}-04$ & $5.01 \mathrm{E}-03$ & Plasma Membrane & other \\
\hline HLA-B & major histocompatibility complex, class I, B & 9.88 & 1.19E-07 & $9.10 \mathrm{E}-05$ & Plasma Membrane & TM receptor \\
\hline HERC5 & HECT and RLD domain containing E3 ubiquitin protein ligase 5 & 9.406 & 3.37E-04 & 7.60E-03 & Cytoplasm & enzyme \\
\hline IFIT3 & interferon induced protein with tetratricopeptide repeats 3 & 9.338 & $3.38 \mathrm{E}-03$ & $3.21 \mathrm{E}-02$ & Cytoplasm & other \\
\hline C8orf4 & chromosome 8 open reading frame 4 & 9.086 & 4.50E-03 & 3.89E-02 & Nucleus & other \\
\hline BST2 & bone marrow stromal cell antigen 2 & 8.941 & 7.45E-06 & $8.54 \mathrm{E}-04$ & Plasma Membrane & other \\
\hline WFDC2 & WAP four-disulfide core domain 2 & 8.632 & 4.25E-06 & $6.15 \mathrm{E}-04$ & Extracellular Space & other \\
\hline SLC6A10P & solute carrier family 6 member 10 , pseudogene & 8.205 & $2.11 \mathrm{E}-08$ & 3.83E-05 & Plasma Membrane & other \\
\hline UBD & ubiquitin D & 8.134 & $2.55 \mathrm{E}-03$ & 2.65E-02 & Nucleus & other \\
\hline CA9 & carbonic anhydrase 9 & 7.177 & 5.84E-06 & 7.39E-04 & Nucleus & enzyme \\
\hline EGLN3 & egl-9 family hypoxia inducible factor 3 & 7.162 & $3.56 \mathrm{E}-06$ & 5.65E-04 & Cytoplasm & enzyme \\
\hline IFI44L & interferon induced protein 44 like & 7.038 & $3.01 \mathrm{E}-04$ & $7.08 \mathrm{E}-03$ & Nucleus & other \\
\hline
\end{tabular}

B.

\begin{tabular}{|c|c|c|c|c|c|}
\hline $\begin{array}{l}\text { Gene } \\
\text { Symbol }\end{array}$ & Entrez Gene Name & FC & P-value & Q-value & Location \\
\hline SPINK7 & $\begin{array}{l}\text { Serine peptidase inhibitor, Kazal type } 7 \\
\text { (putative) }\end{array}$ & -100.36 & $9.34 \mathrm{E}-06$ & $9.50 \mathrm{E}-04$ & Extracellular Space \\
\hline SPRR1A & small proline rich protein $1 \mathrm{~A}$ & -52.265 & 4.20E-07 & 1.84E-04 & Plasma Membrane \\
\hline SPRR2D & small proline rich protein $2 \mathrm{D}$ & -47.922 & $9.74 \mathrm{E}-09$ & 2.71E-05 & Cytoplasm \\
\hline HOPX & HOP homeobox & -47.555 & $1.49 \mathrm{E}-06$ & $3.66 \mathrm{E}-04$ & Nucleus \\
\hline SPRR3 & small proline rich protein 3 & -43.909 & $3.90 \mathrm{E}-07$ & $1.76 \mathrm{E}-04$ & Cytoplasm \\
\hline KLK12 & kallikrein related peptidase 12 & -40.009 & $5.24 \mathrm{E}-07$ & $2.12 \mathrm{E}-04$ & Extracellular Space \\
\hline MAL & mal, T-cell differentiation protein & -38.974 & $1.51 \mathrm{E}-04$ & $4.81 \mathrm{E}-03$ & Plasma Membrane \\
\hline SPRR1B & small proline rich protein $1 \mathrm{~B}$ & -38.958 & $3.56 \mathrm{E}-07$ & $1.72 \mathrm{E}-04$ & Cytoplasm \\
\hline $\mathrm{CDC} 20$ & cell division cycle 20 & -38.096 & $7.49 \mathrm{E}-07$ & $2.68 \mathrm{E}-04$ & Nucleus \\
\hline FST & follistatin & -35.004 & 1.03E-09 & $9.17 \mathrm{E}-06$ & Extracellular Space \\
\hline TGM1 & transglutaminase 1 & -33.664 & 2.04E-07 & $1.20 \mathrm{E}-04$ & Plasma Membrane \\
\hline KRT4 & keratin 4 & -27.508 & $1.39 \mathrm{E}-06$ & $3.66 \mathrm{E}-04$ & Cytoplasm \\
\hline CRCT1 & cysteine rich C-terminal 1 & -27.378 & $2.17 \mathrm{E}-06$ & $4.35 \mathrm{E}-04$ & Other \\
\hline SBSN & suprabasin & -26.217 & $2.00 E-05$ & $1.53 E-03$ & Cytoplasm \\
\hline SPRR2E & small proline rich protein $2 \mathrm{E}$ & -25.018 & $1.52 \mathrm{E}-06$ & $3.69 \mathrm{E}-04$ & Cytoplasm \\
\hline SERPINB2 & serpin family B member 2 & -23.219 & $2.04 \mathrm{E}-07$ & $1.20 \mathrm{E}-04$ & Extracellular Space \\
\hline TOP2A & topoisomerase (DNA) II alpha & -20.766 & 2.26E-04 & $6.07 \mathrm{E}-03$ & Nucleus \\
\hline UBE2C & ubiquitin conjugating enzyme E2 C & -20.293 & $1.07 E-05$ & $1.03 \mathrm{E}-03$ & Cytoplasm \\
\hline SPINK6 & serine peptidase inhibitor, Kazal type 6 & -19.847 & $1.73 \mathrm{E}-03$ & $2.06 \mathrm{E}-02$ & Extracellular Space \\
\hline CCNB2 & cyclin B2 & -18.818 & $9.14 \mathrm{E}-05$ & $3.68 \mathrm{E}-03$ & Cytoplasm \\
\hline
\end{tabular}

Figure 10: Microarray analyses performed on tumor cells from Patient 2. The top 20 genes (A) induced or (B) suppressed under TDCM vs conventional culture conditions are shown. 
surrounded by a fibro-muscular stroma, formed by urogenital sinus (UGS) and mesenchymal cells during embryonic development $[27,28]$. The UGS and stroma are vital for differentiation of the ductal cells. The adult stroma, comprised of smooth muscle cells, fibroblasts and myofibroblasts, is critically important for the maintenance of normal prostate secretory function, and changes in the stromal architecture are associated with $\mathrm{PCa}$ [29]. A recent molecular study of the stroma of low and high Gleason grade PCa found that genes associated with osteoblasts, wound healing and metastasis, among others, were significantly induced in the "activated stroma" of high grade prostate cancers [30], supporting the hypothesis that the stroma supports the proliferation and possibly aggressiveness of PCa cells [31]. While coculture of the CRCs with prostate stromal cells was not modeled in the current study, the TDCM platform is easily amenable to co-culture experiments. Future studies will assess the impact of stromal-epithelial interactions on the morphology and functionality of both normal and tumorderived prostate CRCs.

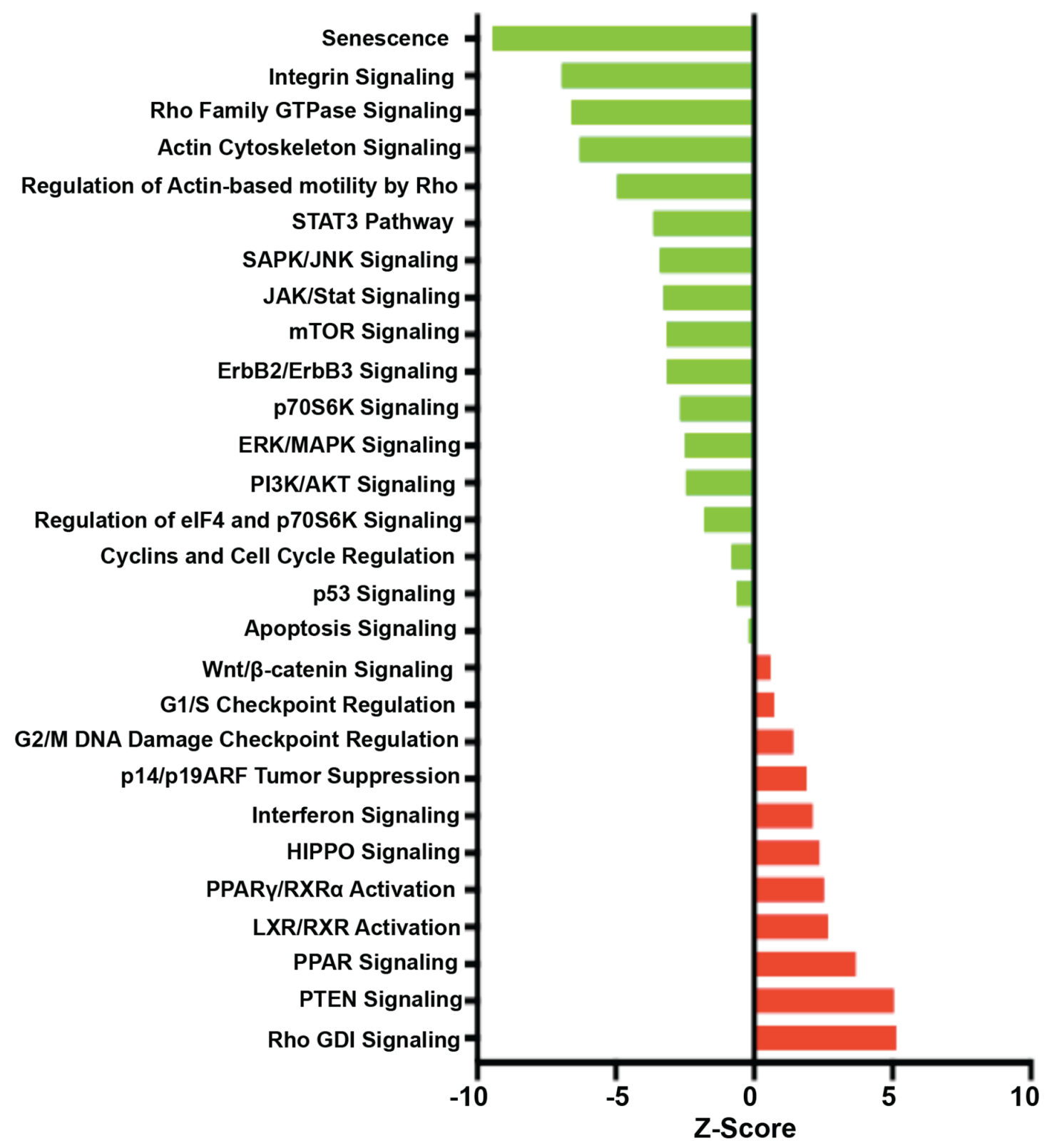

Figure 11: Signaling and regulatory pathway transcriptional regulation. Impact analyses were performed on RNA from tumor-derived CRCs from Patient 2. The z-scores are shown as pathways induced (red) or repressed (green) in under TDCM conditions vs conventional culture conditions. 


\section{MATERIALS AND METHODS}

\section{Cell lines and cell culture}

Human radical prostatectomy samples were collected under the auspices and approval of the Georgetown University and Massachusetts General Hospital Institutional Review Boards. Following detailed pathological analyses that documented that the tissue sections collected were $>70 \%$ tumor cells, the specimens were processed via protease dissociation as previously described [7]. Primary cultures were established at Georgetown University using the CRC method and maintained in co-culture or in conditioned media (CM) as previously described [22]. Genetic profiles, obtained by metaphase spreads on the normal and tumor-derived CRCs, were performed (Supplementary Figure 1). The Gleason 6 and $8 \mathrm{PCa}$ lines remained diploid but showed increasing incidences of chromosomal aberrations, with the Gleason 8 cells from Patient 2 exhibiting numerous translocations and markers. Conversely the PCa3 CRC line, derived from a lymph node organoid line termed PCA3 in [32] was polyploid with extensive chromosomal gains and losses (Supplementary Figure 1). The normal prostate CRCs were diploid 46XY with no known translocations, deletions or cancer markers (not shown).

\section{Defined media}

The defined media are comprised of the commercial prostate cell growth media (PrEGM, Cat. CC-3166) and additional supplements (Table 1). Defined media 5 (DM5), used throughout the study, contains $30 \mathrm{nM}$ citrate, $1 \mathrm{nM}$ zinc, $5 \mathrm{nM}$ Dihydrotestosterone (DHT), $10 \mathrm{ng} / \mathrm{mL}$ Insulinlike Growth Factor 1 (IGF-1) and $10 \mathrm{nM}$ vitamin D3 and is referred to throughout the study as DM.

\section{Transwell dish culture model (TDCM)}

The CRC cultures were established and maintained as previously described by us [21]. Briefly, the prostate CRCs were grown on a $0.4 \mu \mathrm{m}$ Millicell filter insert (Becton Dickinson) placed in a 6 well tissue culture dish. The filter inserts are first treated with a gelatin coating to help limit diffusion between the chambers [21]. Next, $6 \times 10^{5}$ CRCs were seeded on the filter insert and CM containing $10 \mathrm{uM} \mathrm{Y-27632} \mathrm{was} \mathrm{placed} \mathrm{in} \mathrm{both}$ the upper and lower chambers. After 7 days, DM or $\mathrm{CM}$ was applied to the top chamber and fresh $\mathrm{CM}$ was added to the bottom chamber. The cells were cultured for one week with frequent media changes. At the end of the study the inserts were removed for histology, immunostaining, protein, DNA and/or RNA extraction as described [21].

\section{Western blot analysis}

Protein extracts were separated on $4-20 \%$ trisglycine gels and electro-blotted onto PVDF membranes. Protein levels were assessed using antibodies against the AR (Santa Cruz Biotechnology, CA \#816), p63 (Santa Cruz Biotechnology, CA \#8431), p27 (Santa Cruz Biotechnology, CA \#528), CK8/18 (Cell Signaling, Danvers, MA \#4546), $\beta$-Actin (Cell Signaling, Danvers, MA \#4967), Oct4 (Cell Signaling, Danvers, MA \#2750), Nanog (Cell Signaling, Danvers, MA \#4903) and SOX2 (Cell Signaling, Danvers, MA \#3579).

\section{Immunohistochemistry and histology}

The filters and cells were fixed in formalin overnight and processed by the Georgetown-Lombardi Histology and Tissue Shared Resource as previously described [21]. For immunohistochemical staining Five micron sections from formalin fixed paraffin embedded tissues were de-paraffinized with xylenes and rehydrated through a graded alcohol series. Heat induced epitope retrieval (HIER) was performed by immersing the tissue sections at $98^{\circ} \mathrm{C}$ for 20 minutes in $10 \mathrm{mM}$ citrate buffer ( $\mathrm{pH} 6.0$ ) with $0.05 \%$ Tween. Slides were treated with $3 \%$ hydrogen peroxide, avidin/biotin blocking, and 10\% normal goat serum and exposed to primary antibodies against the AR (1:80 dilution, Santa Cruz sc-816) overnight at $4^{\circ} \mathrm{C}$, then against p63 (1:400 dilution, Santa Cruz sc-816) for 1 hour at room temperature. Slides were exposed to goat anti-mouse biotin-conjugated (Vector Labs) and goat antirabbit-488 (Thermofisher) secondary antibodies, and Cy3SA (Thermofisher). Autofluorescence was quenched with Sudan Black and the slides mounted in Pro-Long Antifade with DAPI (Thermofisher). Consecutive sections with the primary antibody omitted were used as negative controls. Fluorescent images were captured using an QImaging camera on an Olympus BX61 microscope.

\section{RPPA proteome analysis}

Cell pellets were isolated from the conventional or TDCM cultures and washed $3 \mathrm{x}$ with PBS as detailed by us [21]. Protein lysates were collected and Reverse Phase Protein Arrays (RPPA) were performed as previously described [25].

\section{Microarray analysis}

RNA from conventional CRC cultures was isolated from cell pellets using an RNA easy kit (Qiagen Cat No. 74104). RNA was isolated from the TDCM cultures as detailed by us [21]. Expression analysis was performed in the Georgetown-Lombardi Genomics and Epigenomics Shared Resource using HumanHT-12 v4 Expression BeadChip. Briefly, normalized data were imported into 
the $\mathrm{R}$ computing environment and analyzed using the Linear Models for Microarray Data package (LIMMA, 3.30.13 [33]) as part of the larger Bioconductor project (http://www.Bioconductor.org) [34]. A linear model was fit for the normalized log ratios of every gene using the 'ImFit' function within LIMMA to estimate all systematic variability in the data. Using functions in LIMMA, pairwise comparisons were performed between tumor cells cultured in TDCM differentiating media and conventional culture media to compute moderated t-statistics, log-odds ratios of differential expression (based on empirical Bayes for shrinkage of standard errors), and adjusted p-values using the BenjaminiHochberg method [35].

\section{Functional analysis}

Gene interaction networks, biological functions and pathway analyses were generated by Ingenuity Pathway Analysis (IPA) (Ingenuity Systems; Mountain View, CA, USA), with microarray data interpretation via grouping of differentially expressed genes into known functions, pathways, and networks primarily based on human and rodent studies. The identified genes were mapped to molecular functions and genetic networks available from the Ingenuity database. The significance was set at a $p$ value and adjusted $p$-value of 0.05 and a fold change of 1.5. From the complete data set of TDCM vs conventional CRC cells, 4367 molecules were eligible for core functional analysis by IPA.

The functional analysis identified the biological functions and the canonical signaling pathways that were most significant to the input data set. The significance of the association between the input data set and the functions or pathways was determined based on three parameters: (1) a ratio of the number of genes from the data set that map to the function/pathway divided by the total number of genes that map to the function/pathway (Overlap percentage) and (2) a $P$-value calculated using Fischer's exact test determining the probability that the association between the genes in the dataset and the function/pathway is explained by chance alone 3) z-score is a statistical measure of the match between expected relationship direction and observed gene expression. The calculated z-score predicts activation or inhibition of a pathway based on positive or negative z-score, respectively.

\section{Abbreviations}

CRC; conditionally reprogrammed cells, $\mathrm{PCa}$; prostate cancer, PSA; prostate specific antigen, AR; androgen receptor, TDCM; transwell dish culture method, DM; defined media, CM; conditioned media, 2D; two dimensional, IPA; Ingenuity Pathways Analysis, LCM; laser capture microdissection, RPPA; reverse phase protein array.

\section{Author contributions}

Drs. Albanese, Tricoli, Petricoin, Feldman, Lee, Rodriguez, Parasido and Naeem conceived and initiated the project and were directly involved in writing and editing the manuscript. Drs Byers, Avantaggiati, Kumar were instrumental in experimental design, data interpretation and writing and editing the manuscript. Drs. Tricoli, Choudhry, Abdelgawad and Naeem perform the cell based experiments. Proteome analyses were performed by Drs. Petricion, Gallagher and Wulfkuhle. The histology and immunofluorescent staining was performed by Dr. Berry, and the in silico analyses were performed by Dr. Naeem and John P. Mikhiael.

\section{ACKNOWLEDGMENTS}

In addition, the following Georgetown-Lombardi Comprehensive Cancer Center core facilities were used throughout the study: the Genomics and Epigenomics Shared Resource, the Cell Culture Shared Resource and the Histopathology \& Tissue Shared Resources which are supported in part by NIH/NCI grant P30-CA051008. The content is solely the responsibility of the authors and does not necessarily represent the official views of the National Cancer Institute or the National Institutes of Health. We thank Charles Sawyers and Yu Chen for the PCa3 organoids and Xuefeng Liu and Richard Schlegel for support and advice.

\section{CONFLICTS OF INTEREST}

The authors declare no conflicts of interest.

\section{FUNDING}

The work was supported by DOD grants W81XWH 13-1-0327(CA) and W81XHW-15-1-0288 (CA) and NIH grants, CTSA TR000102 (CA, LT) U01 CA194730 (DK, CA) and P30-CA051008 (LW).

\section{REFERENCES}

1. Prensner JR, Rubin MA, Wei JT, Chinnaiyan AM. Beyond PSA: the next generation of prostate cancer biomarkers. Sci Transl Med. 2012; 4:127rv3. https://doi.org/10.1126/ scitranslmed.3003180.

2. Coutinho I, Day TK, Tilley WD, Selth LA. Androgen receptor signaling in castration-resistant prostate cancer: a lesson in persistence. Endocr Relat Cancer. 2016; 23:T179-T97. https://doi.org/10.1530/ERC-16-0422.

3. Hensley PJ, Kyprianou N. Modeling prostate cancer in mice: limitations and opportunities. J Androl. 2012; 33:133-44. 
4. Gao D, Vela I, Sboner A, Iaquinta PJ, Karthaus WR, Gopalan A, Dowling C, Wanjala JN, Undvall EA, Arora VK, Wongvipat J, Kossai M, Ramazanoglu S, et al. Organoid Cultures Derived from Patients with Advanced Prostate Cancer. Cell. 2014; 159:176-87.

5. Boj SF, Hwang CI, Baker LA, Chio II, Engle DD, Corbo V, Jager M, Ponz-Sarvise M, Tiriac H, Spector MS, Gracanin A, Oni T, Yu KH, et al. Organoid models of human and mouse ductal pancreatic cancer. Cell. 2014; 160:324-38.

6. Chapman S, Liu X, Meyers C, Schlegel R, McBride AA. Human keratinocytes are efficiently immortalized by a Rho kinase inhibitor. J Clin Invest. 2010; 120:2619-26.

7. Liu X, Ory V, Chapman S, Yuan H, Albanese C, Kallakury B, Timofeeva O, Nealon C, Dalic A, Simic V, Haddad B, Rhim J, Dritschilo A, et al. ROCK inhibitor and feeder cells induce the conditional reprogramming of epithelial cells. American Journal of Pathology. 2012; 180:590-607.

8. Liu X, Krawczyk E, Suprynowicz FA, Palechor-Ceron N, Yuan H, Dakic A, Simic V, Zheng YL, Sripadhan P, Chen C, Lu J, Hou TW, Choudhury S, et al. Conditional reprogramming and long-term expansion of normal and tumor cells from human biospecimens. Nat Protoc. 2017; 12:439-51. https://doi.org/10.1038/nprot.2016.174.

9. Suprynowicz FA, Upadhyay G, Krawczyk E, Kramer SC, Hebert JD, Liu X, Yuan H, Cheluvaraju C, Clapp PW, Boucher RC Jr, Kamonjoh CM, Randell SH, Schlegel R. Conditionally reprogrammed cells represent a stem-like state of adult epithelial cells. Proc Natl Acad Sci U S A. 2012; 109:20035-40.

10. Yuan H, Myers S, Wang J, Zhou D, Woo JA, Kallakury B, Ju A, Bazylewicz M, Carter YM, Albanese C, Grant N, Shad A, Dritschilo A, et al. Use of reprogrammed cells to identify therapy for respiratory papillomatosis. N Engl J Med. 2012; 367:1220-7.

11. Ringer L, Sirajuddin P, Tricoli L, Waye S, Parasido E, Lee RJ, Feldman A, Wu CL, Dritschilo A, Lynch J, Schlegel $\mathrm{R}$, Rodriguez $\mathrm{O}$, Pestell RG, et al. The Induction of the p53 Tumor Suppressor Protein Bridges the Apoptotic and Autophagic Signaling Pathways to Regulate Cell Death in Prostate Cancer Cells. Oncotarget. 2014; 5:10678-91. https://doi.org/10.18632/oncotarget.2528.

12. Pollock CB, McDonough S, Wang VS, Lee H, Ringer L, Li X, Prandi C, Lee RJ, Feldman AS, Koltai H, Kapulnik Y, Rodriguez OC, Schlegel R, et al. Strigolactone analogues induce apoptosis through activation of p38 and the stress response pathway in cancer cell lines and in conditionally reprogramed primary prostate cancer cells. Oncotarget. 2014; 5:1683-98. https://doi.org/10.18632/oncotarget.1849.

13. Croglio MP, Haake JM, Ryan CP, Wang VS, Lapier J, Schlarbaum JP, Dayani Y, Artuso E, Prandi C, Koltai H, Agama K, Pommier Y, Chen Y, et al. Analogs of the novel phytohormone, strigolactone, trigger apoptosis and synergize with PARP inhibitors by inducing DNA damage and inhibiting DNA repair. Oncotarget. 2016; 7:139844001. https://doi.org/10.18632/oncotarget.7414.
14. Saeed K, Rahkama V, Eldfors S, Bychkov D, Mpindi JP, Yadav B, Paavolainen L, Aittokallio T, Heckman C, Wennerberg K, Peehl DM, Horvath P, Mirtti T, et al. Comprehensive Drug Testing of Patient-derived Conditionally Reprogrammed Cells from Castrationresistant Prostate Cancer. Eur Urol. 2017; 71:319-27. https://doi.org/10.1016/j.eururo.2016.04.019.

15. Yuan H, Krawczyk E, Blancato J, Albanese C, Zhou D, Wang N, Paul S, Alkhilaiwi F, Palechor-Ceron N, Dakic A, Fang S, Choudhary S, Hou TW, et al. HPV positive neuroendocrine cervical cancer cells are dependent on Myc but not E6/E7 viral oncogenes. Sci Rep. 2017; 7:45617. https://doi.org/10.1038/srep45617.

16. Timofeeva OA, Palechor-Ceron N, Li G, Yuan H, Krawczyk E, Zhong X, Liu G, Upadhyay G, Dakic A, Yu S, Fang S, Choudhury S, Zhang X, et al. Conditionally reprogrammed normal and primary tumor prostate epithelial cells: a novel patient-derived cell model for studies of human prostate cancer. Oncotarget. 2017; 8:22741-58. https://doi. org/10.18632/oncotarget.13937.

17. McAuliffe PF, Evans KW, Akcakanat A, Chen K, Zheng X, Zhao H, Eterovic AK, Sangai T, Holder AM, Sharma C, Chen H, Do KA, Tarco E, et al. Ability to Generate Patient-Derived Breast Cancer Xenografts Is Enhanced in Chemoresistant Disease and Predicts Poor Patient Outcomes. PLoS One. 2015; 10:e0136851. https://doi. org/10.1371/journal.pone.0136851.

18. Gentzsch M, Boyles SE, Cheluvaraju C, Chaudhry IG, Quinney NL, Cho C, Dang H, Liu X, Schlegel R, Randell SH. Pharmacological Rescue of Conditionally Reprogrammed Cystic Fibrosis Bronchial Epithelial Cells. Am J Respir Cell Mol Biol. 2016; 56:568-574. https://doi. org/10.1165/rcmb.2016-0276MA.

19. Yu D, Davis RM, Aita M, Burns KA, Clapp PW, Gilmore RC, Chua M, O'Neal WK, Schlegel R, Randell SH, C Boucher R. Characterization of Rat Meibomian Gland Ion and Fluid Transport. Invest Ophthalmol Vis Sci. 2016; 57:2328-43. https://doi.org/10.1167/iovs.15-17945.

20. Crystal AS, Shaw AT, Sequist LV, Friboulet L, Niederst MJ, Lockerman EL, Frias RL, Gainor JF, Amzallag A, Greninger P, Lee D, Kalsy A, Gomez-Caraballo M, et al. Patient-derived models of acquired resistance can identify effective drug combinations for cancer. Science. 2014; 346:1480-6. https://doi.org/10.1126/science.1254721.

21. Tricoli L, Berry D, Albanese C. A rapid 3D filter-based $3 \mathrm{D}$ culture system for primary prostate cell differentiation. JoVE. 2017. [Epub ahead of print].

22. Palechor-Ceron N, Suprynowicz FA, Upadhyay G, Dakic A, Minas T, Simic V, Johnson M, Albanese C, Schlegel R, Liu X. Radiation Induces Diffusible Feeder Cell Factor(s) That Cooperate with ROCK Inhibitor to Conditionally Reprogram and Immortalize Epithelial Cells. Am J Pathol. 2013; 183:1862-70.

23. Nyame YA, Murphy AB, Bowen DK, Jordan G, Batai K, Dixon M, Hollowell CM, Kielb S, Meeks JJ, Gann 
PH, Macias V, Kajdacsy-Balla A, Catalona WJ, et al. Associations Between Serum Vitamin D and Adverse Pathology in Men Undergoing Radical Prostatectomy. J Clin Oncol. 2016; 34:1345-9. https://doi.org/10.1200/ JCO.2015.65.1463

24. Cai C, He HH, Chen S, Coleman I, Wang H, Fang Z, Chen S, Nelson PS, Liu XS, Brown M, Balk SP. Androgen receptor gene expression in prostate cancer is directly suppressed by the androgen receptor through recruitment of lysine-specific demethylase 1. Cancer Cell. 2011; 20:45771. https://doi.org/10.1016/j.ccr.2011.09.001.

25. Parasido EM, Silvestri A, Canzonieri V, Belluco C, Diodoro MG, Milione M, Melotti F, De Maria R, Liotta L, Petricoin EF, Pierobon M. Protein drug target activation homogeneity in the face of intra-tumor heterogeneity: implications for precision medicine. Oncotarget. 2017; 8:48534-44. https:// doi.org/10.18632/oncotarget.14019.

26. Reutens AT, Fu M, Wang C, Albanese C, McPhaul MJ, Sun Z, Balk SP, Janne OA, Palvimo JJ, Pestell RG. Cyclin $\mathrm{D} 1$ binds the androgen receptor and regulates hormonedependent signaling in a p300/CBP-associated factor (P/CAF)-dependent manner. Mol Endocrinol. 2001; 15:797-811.

27. Cunha GR, Hayward SW, Dahiya R, Foster BA. Smooth muscle-epithelial interactions in normal and neoplastic prostatic development. Acta Anat (Basel). 1996; 155:63-72.

28. Hayward SW, Baskin LS, Haughney PC, Cunha AR, Foster BA, Dahiya R, Prins GS, Cunha GR. Epithelial development in the rat ventral prostate, anterior prostate and seminal vesicle. Acta Anat (Basel). 1996; 155:81-93.

29. Wong YC, Tam NN. Dedifferentiation of stromal smooth muscle as a factor in prostate carcinogenesis.
Differentiation. 2002; 70:633-45. https://doi. org/10.1046/j.1432-0436.2002.700916.x.

30. Tyekucheva S, Bowden M, Bango C, Giunchi F, Huang Y, Zhou C, Bondi A, Lis R, Van Hemelrijck M, Andren $\mathrm{O}$, Andersson SO, Watson RW, Pennington $\mathrm{S}$, et al. Stromal and epithelial transcriptional map of initiation progression and metastatic potential of human prostate cancer. Nat Commun. 2017; 8:420. https://doi.org/10.1038/ s41467-017-00460-4.

31. Barron DA, Rowley DR. The reactive stroma microenvironment and prostate cancer progression. Endocr Relat Cancer. 2012; 19:R187-204. https://doi.org/10.1530/ ERC-12-0085.

32. Robinson D, Van Allen EM, Wu YM, Schultz N, Lonigro RJ, Mosquera JM, Montgomery B, Taplin ME, Pritchard CC, Attard G, Beltran H, Abida W, Bradley RK, et al. Integrative clinical genomics of advanced prostate cancer. Cell. 2015; 161:1215-28.

33. Wettenhall JM, Smyth GK. limmaGUI: a graphical user interface for linear modeling of microarray data. Bioinformatics. 2004; 20:3705-6. https://doi.org/10.1093/ bioinformatics/bth449.

34. Dudoit S, Gentleman RC, Quackenbush J. Open source software for the analysis of microarray data. Biotechniques. 2003; 45-51.

35. Klipper-Aurbach Y, Wasserman M, Braunspiegel-Weintrob N, Borstein D, Peleg S, Assa S, Karp M, Benjamini Y, Hochberg Y, Laron Z. Mathematical formulae for the prediction of the residual beta cell function during the first two years of disease in children and adolescents with insulin-dependent diabetes mellitus. Med Hypotheses. 1995; 45:486-90. 